\title{
Study of the effectiveness of the US safety standard for child resistant cigarette lighters
}

\author{
L E Smith, M A Greene, H A Singh
}

Injury Prevention 2002;8:192-196

\begin{abstract}
Objective: The purpose of this research is to evaluate the effectiveness of the US Consumer Product Safety Commission's (CPSC) Safety Standard for Cigarette Lighters, which requires that disposable cigarette lighters be resistant to operation by children younger than age 5 .

Methods: Fire data on children playing with lighters were solicited from selected US fire departments for incidents occurring from 1997-99, to identify the proportion of such fires caused by children younger than age 5 playing with cigarette lighters. These data were compared with similar data from 1985-87. An odds ratio was used to determine if there was a significant decrease in cigarette lighter fires caused by children younger than age 5 compared to children ages 5 and older. To estimate fires that would have occurred without the standard, the odds ratio, adjusted for population, was applied to 1998 national estimates of fires occurring. National estimates of 1998 fire losses were based on data from the National Fire Incident Reporting System and the National Fire Protection Association to which the 1997-99 age and lighter type distributions were applied. The difference between the fire losses that would have occurred and those that did occur represented fire losses prevented.

Results: In the post-standard study, $48 \%$ of the cigarette lighter fires were started by children younger than age 5 , compared with $71 \%$ in the pre-standard study. The odds ratio of 0.42 was statistically significant $(p<0.01)$. This represented a $58 \%$ reduction in fires caused by the younger age group compared to the older age group. When applied to national fire loss data, an estimated 3300 fires, 100 deaths, 660 injuries, and $\$ 52.5$ million in property loss were prevented by the standard in 1998, totaling $\$ 566.8$ million in 1998 societal savings.

Conclusions: The CPSC standard requiring child resistant cigarette lighters has reduced fire deaths, injuries, and property loss caused by children playing with cigarette lighters and can be expected to prevent additional fire losses in subsequent years.
\end{abstract}

See end of article for

n

n 1985, the US Consumer Product Safety Commission (CPSC) was petitioned to begin rulemaking to require disposable cigarette lighters to be resistant to operation by children. Subsequently, the US CPSC estimated that children younger than age 5 playing with cigarette lighters ignited 5900 residential fires that resulted in 170 deaths and 1150 injuries annually for the period 1986-88. ${ }^{1}$ Disposable lighters were involved in $97 \%$ of those fires and accounted for about $95 \%$ of the estimated 488 million disposable lighters sold annually during that period. ${ }^{2}$

In response to those findings, CPSC developed the Safety Standard for Cigarette Lighters (16 CFR Part 1210), which applies to products manufactured or imported after 12 July 1994. The standard requires disposable and novelty cigarette lighters to have a child resistant mechanism that makes the lighters difficult for children younger than age 5 to operate. A lighter with one type of child resistant ignition mechanism is shown in fig 1 . The definition of disposable lighters includes non-refillable lighters and inexpensive refillable lighters. Novelty lighters are defined as those that resemble or depict articles appealing to children younger than age 5, or that have entertaining audio or visual effects. Novelty lighters may be either disposable or refillable. The standard excludes "multipurpose" lighters such as those used to light barbecue grills and fireplaces, which were not evident as a child play hazard when work on the standard occurred. These lighters now are covered by a separate standard (16 CFR Part 1212) which took effect for products manufactured or imported after 22 December 2000 .

The child resistance of a cigarette lighter is determined by tests conducted by lighter manufacturers using panels of children between the ages of 42 and 51 months. Lighters used for the tests have no fuel. When activated, they produce an audible or visual signal. Child resistant lighters must be designed so that at least $85 \%$ of children included in the test panel are not able to operate the lighters under timed test conditions.

The purpose of this paper is to evaluate the effect of the Safety Standard for Cigarette Lighters. Based on information indicating that disposable cigarette lighters have an average product life of two to three months, CPSC concluded that virtually all disposable cigarette lighters in US households would be child resistant by late 1997 and initiated a study to evaluate the effectiveness of the standard.

\section{METHODS}

In brief, the evaluation of standard effectiveness involved three phases. The first phase involved a comparison of the age distributions of children playing with cigarette lighters before and after the standard, based on two CPSC studies. The result was an odds ratio comparing the reduction in fires among the younger age group (affected by the standard) to the reduction among the older age group (not affected by the standard). The second phase involved application of the post-standard CPSC study age and lighter type distributions to national estimates of fire losses derived from National Fire Protection Association (NFPA) and National Fire Incident Reporting System (NFIRS) data, to estimate fire losses that were still occurring after the standard. The third and final phase involved application of the

Abbreviations: CPSC, Consumer Product Safety Commission; NFPA, National Fire Protection Association; NFIRS, National Fire Incident Reporting System 


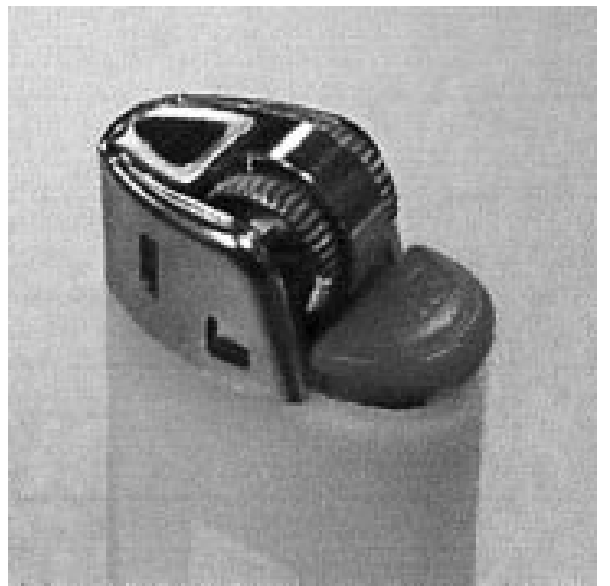

Figure 1 Cigarette lighter with a child resistant ignition mechanism. Note: This is one of many types of child resistant mechanisms. The metal shield must be depressed before the sparkwheel can be turned to produce a spark. The force required to depress the shield is difficult for young children to achieve.

odds ratio to the post-standard estimates to estimate hypothetical losses that would have occurred without the standard. The difference represented fire losses prevented. Datasets used in this paper are listed in table 1 and described below.

\section{Phase 1: comparison of the age distributions}

The before and after standard age distributions were identified in two CPSC data collection studies. The pre-standard data collection occurred from $1985-87 .{ }^{4}$ CPSC field staff across the country contacted fire jurisdictions in their local areas requesting notification of all fires started by children playing with cigarette lighters as they occurred during the ongoing data collection period. A total of 113 fires involving children playing with lighters were reported to CPSC by the fire service. CPSC field staff then completed a follow up investigation identifying the age of the child who started the fire, the characteristics of the lighter involved, fire casualties, property loss, and a description of the incident scenario.

After implementation of the standard, CPSC conducted a second data collection during the period October 1997 to February 1999. As in the first study, CPSC's field offices requested notification from nearby fire jurisdictions on all fires started by children playing with lighters as they occurred. Participating fire departments submitted their fire incident and investigation reports documenting fire cause for all fires that involved a child playing with any type of lighter. When a child younger than age 5 started the fire, the fire department also completed a CPSC questionnaire providing additional detail on the age of the child and the lighter characteristics. Lighters used in fires started by children younger than age 5 were collected whenever possible. The study included reports from 108 local fire jurisdictions in 31 states and consisted of 375 fires that resulted in 23 deaths and 95 injuries. Lighter type was identified in all but seven of the 375 fires.

In both studies, fires attended by the fire service that were caused by children playing with lighters were identified via a set of standardized incident codes contained in the NFIRS. Fire departments were requested to report to CPSC every incident that met these specific criteria and submit their standard fire cause documents, a fire incident report and an investigation report, to CPSC. Although the fire service has no universally accepted definition of when a fire should be considered child play rather than arson, the decision is usually based on the perceived ability of the child to understand the consequences of his actions.

Since lighter fires may have decreased for reasons other than the standard, the analysis focused on the change in the proportion of cigarette lighter fires caused by children younger than age 5 (affected by the standard) compared to children age 5 and older (not affected by the standard). The procedure had the effect of controlling for a variety of other factors that were likely to have contributed to a reduction of fire losses over the years.

Odds ratio methods were used for the comparison. Children younger than age 5 were considered the treatment group $t$. Children ages 5 and older were considered the comparison group $c$. Time periods before and after the standard were designated $b$ and $a$ respectively, with $n$ representing the number of incidents. The odds that an event occurred before the standard for the treatment group was:

\section{ODDS treatment $=n_{t b} / n_{t a}$}

with the analogous expression for the control group. The incident odds ratio, was then defined as ODDS comparison/ODDS treatment. An additional adjustment was made for changes in the US population at risk in the two time periods because a decrease in the relative proportion of children younger than age 5 in the population could be confounded with the effect of the standard. To adjust for the change in population, we calculated the population odds ratio for children younger than age 5 and ages 5-9 in the general population in both time periods and applied it to the crude odds ratio from the two studies. Confidence intervals and hypothesis tests used the standard error for the odds ratio found in Fleiss (1981, equation 5.19 , page 63$).^{5}$

\section{Phase 2: national estimates}

To translate the odds ratio into prevented fire losses, we first estimated post-standard fire losses. This was done by applying the fire starter age and lighter type distributions from the post-standard CPSC data collection to 1998 national estimates

Table 1 Data sources

\begin{tabular}{|c|c|c|c|}
\hline Dataset & Dates & Data provided & Data source \\
\hline $\begin{array}{l}\text { CPSC pre-standard study of lighter } \\
\text { child play fires }\end{array}$ & $1985-87$ & $\begin{array}{l}\text { Age distribution of children who started fires by } \\
\text { playing with cigarette lighters }\end{array}$ & $\begin{array}{l}\text { Lighter child play fires attended by solicited fire } \\
\text { departments }\end{array}$ \\
\hline $\begin{array}{l}\text { CPSC post-standard study of lighter } \\
\text { child play fires }\end{array}$ & 1997-99 & $\begin{array}{l}\text { Age distribution of children who started fires by } \\
\text { playing with cigarette lighters }\end{array}$ & $\begin{array}{l}\text { Lighter child play fires attended by solicited fire } \\
\text { departments }\end{array}$ \\
\hline NFPA & All years & $\begin{array}{l}\text { Estimates of US residential structure fires attended } \\
\text { by fire departments }\end{array}$ & Probability survey of public fire departments \\
\hline NFIRS* & All years & $\begin{array}{l}\% \text { Of residential structure fires in NFIRS that } \\
\text { involve children playing with lighters }\end{array}$ & $\begin{array}{l}\text { Fire incident reports from local fire departments. } \\
\text { NFIRS captured about } 40 \% \text { of residential fires } \\
\text { attended by fire departments in } 1998 \text {, as } \\
\text { estimated by NFPA }\end{array}$ \\
\hline
\end{tabular}

* Lighter fires involving children playing are identified in NFIRS from ignition factors 36 and 48 (child play), form of heat ignition 46 (lighter), equipmen involved in ignition 98 or 99 (no specific equipment), type of situation 11 (structure fire), and fixed property use 4 (residential). 
Table 2 Age distributions of the fire starters playing with cigarette lighters in two CPSC studies

\begin{tabular}{llll}
\hline Age distribution (years) & $1985-87$ & $1997-99$ & Odds \\
\hline $0-4$ & 80 & 144 & 0.56 \\
$\geqslant 5$ & 33 & 154 & 0.21 \\
\% Ages 0-4 & 71 & 48 & \\
Crude odds ratio & & & 0.39 \\
Age adjusted odds ratio & & & $0.42^{*}$ \\
95\% Confidence interval & & & 0.23 to 0.62 \\
\hline
\end{tabular}

Note: One incident with unknown age or lighter type was deleted from the 1997-99 study. The age adjusted odds ratio was derived by dividing the crude odds ratio by the population odds ratio. *The odds ratio was statistically significant, $z=-4.24, p<0.01$.

of residential fires caused by children playing with lighters, based on NFPA and NFIRS data.

The NFPA survey is based on a stratified random sample of fire departments in the US and provides annual estimates of all residential structure fires, deaths, injuries, and estimated property loss. It does not identify fire cause. ${ }^{6}$

Fires caused by children playing with lighters were identified in the NFIRS. NFIRS is a compilation of fire incident reports completed by US fire departments on fires they attend. Reports are submitted voluntarily to the US Fire Administration, which assembles the reports to construct the NFIRS database. In 1998, NFIRS contained 156600 residential structure fires, about $40 \%$ of the residential structure fires estimated by NFPA. The NFIRS reporting code that identifies lighters includes both cigarette and multipurpose lighters. Age of the fire starter is not included. While NFIRS is not a probability sample, the US Fire Administration has stated that to the best they can determine, the distribution of participating fire departments is reasonably representative of the entire nation.

To develop 1998 fire loss estimates for all ages of children playing with all types of lighters, the percentage of all NFIRS residential structure fires that involved children playing with lighters was calculated. Unknown values of the variables used in the analysis were allocated proportionally among the known values. ${ }^{89}$ The process was repeated for deaths, injuries, and property loss. Then, the percentages were applied to NFPA estimates of US residential structure fires and fire losses (deaths, injuries, and property loss) to provide national estimates of US residential structure fires and losses that involved all ages of children playing with all types of lighters. ${ }^{10}$

Estimates of 1998 fire losses by age group and lighter type were developed by applying the 1997-99 study age and lighter type distributions to the 1998 national estimates of all lighter child play fires and fire losses.

\section{Phase 3: fire losses prevented}

Finally, fire losses prevented by the standard were computed. If the standard had no effect, then one could expect that the rate of change in fires involving the treatment group (children younger than age 5) from 1985-87 and 1997-99 would have been the same as the comparison group. This would put the hypothetical sample estimate for fires caused by children younger than age 5 as $n^{*}{ }_{t a}=n_{t a} / O R$ where $O R$ is the age adjusted odds ratio. Incidents saved would then $n^{*}{ }_{t a}-n_{t a}$ or $n_{t a}(1-1 / O R)$. To obtain national estimates, the national estimate of fires caused by children younger than age 5 was inserted in the formulas above.

Hypothetical deaths, injuries, and property loss were derived by first calculating the 1998 per fire rates of estimated death, injury, and property loss caused by children younger than age 5 playing with cigarette lighters. Then, the rates were multiplied by the estimate of hypothetical fires, to obtain estimates of the hypothetical number of fire deaths and injuries,
Table 3 Estimated 1998 residential structure lighter child play fire losses attended by the fire service

\begin{tabular}{|c|c|c|c|}
\hline \multirow[b]{2}{*}{ Loss measure and lighter type } & \multirow[b]{2}{*}{ Total } & \multicolumn{2}{|c|}{ Age of fire starter } \\
\hline & & Age $<5$ & Age $\geqslant 5$ \\
\hline \multicolumn{4}{|l|}{ Fires $(n=375)$} \\
\hline Total & 6100 & 3100 & 3000 \\
\hline Cigarette & 5000 & 2400 & 2600 \\
\hline Multipurpose & 1100 & 800 & 400 \\
\hline \multicolumn{4}{|l|}{ Deaths $(n=23)$} \\
\hline Total & 130 & 90 & 40 \\
\hline Cigarette & 90 & 70 & 20 \\
\hline Multipurpose & 50 & 20 & 20 \\
\hline \multicolumn{4}{|l|}{ Injuries ( $n=95$ ) } \\
\hline Total & 810 & 530 & 280 \\
\hline Cigarette & 670 & 480 & 200 \\
\hline Multipurpose & 140 & 50 & 90 \\
\hline \multicolumn{4}{|l|}{ Property loss (\$millions) $(n=\$ 7.1)$} \\
\hline Total & 99.0 & 53.7 & 45.3 \\
\hline Cigarette & 79.8 & 38.2 & 41.7 \\
\hline Multipurpose & 19.2 & 15.6 & 3.6 \\
\hline
\end{tabular}

Note: Detail may not add due to rounding. All estimates were rounded; fires to the nearest hundred, deaths and injuries to the nearest ten, and estimated property loss to the nearest tenth of a million dollars.

and amount of property loss that would have occurred in those fires. The difference between the hypothetical fire losses and the 1998 fire losses that occurred represented the losses prevented by the standard.

The overall societal cost associated with the fire losses was calculated by summing the estimated monetary value of the deaths, injuries, and estimated property loss involved. CPSC's Directorate for Economic Analysis valued each death at \$5 million and each injury at $\$ 50000 .{ }^{11}{ }^{12}$

\section{RESULTS}

\section{Estimate of standard effectiveness}

Table 2 presents the age distribution of the children who started cigarette lighter child play fires in the two CPSC studies, one pre-standard and one post-standard. The table shows that $71 \%$ of the fires were started by children younger than age 5 in the 1985-87 study, while $48 \%$ of the incidents were started by children younger than age 5 in the 1997-99 study. The age adjusted odds ratio of 0.42 was statistically significant $(p<0.01)$, with a $95 \%$ confidence interval of 0.23 to 0.62 . This suggests that the standard was associated with a 58\% reduction in cigarette lighter fires caused by children younger than age 5 .

\section{National estimates of post-standard fire losses}

Application of post-standard age and lighter type distributions to 1998 national estimates of all fires caused by children playing with lighters indicated that children younger than age 5 caused an estimated 2400 cigarette lighter fires that resulted in 70 deaths, 480 injuries, and $\$ 38.2$ million in property loss in 1998 (table 3). Among only cigarette lighter fires, children younger than age 5 ignited an estimated $48 \%$ of the fires that resulted in $80 \%$ of the deaths, $71 \%$ of the injuries, and $48 \%$ of the property loss. Less than $1 \%$ of the cigarette lighter fires caused by children younger than age 5 involved novelty lighters, the same proportion as in the pre-standard data.

\section{National estimates of fire losses prevented}

Table 4 presents 1998 estimated cigarette lighter fires and fire losses caused by children younger than age 5 that would have occurred if the standard had no effect. This estimate of 5700 cigarette lighter fires is 3300 more fires than the 1998 estimate of fires that occurred. The actual fire estimate of 2400 represents a 58\% reduction from the "no effect" estimate. 
Table 4 Estimated 1998 cigarette lighter child play fire losses prevented by the CPSC standard

\begin{tabular}{llllll}
\hline Case & Fires & Deaths & Injuries & $\begin{array}{l}\text { Property } \\
\text { loss } \\
\text { (\$millions) }\end{array}$ & $\begin{array}{l}\text { Total societal } \\
\text { cost } \\
\text { (\$millions) }\end{array}$ \\
\hline $\begin{array}{l}\text { Actual 1998 fire losses } \\
\begin{array}{l}\text { 1998 Expected fire losses if standard had } \\
\text { no effect } \\
1998 \text { Fire losses prevented }\end{array}\end{array}$ & 2400 & 70 & 480 & 38.2 & 412.2 \\
\hline
\end{tabular}

Table 5 Lighters involved in fires ignited by children younger than age 5, 1997-99

\begin{tabular}{llll}
\hline Lighter type & No of fires & $\begin{array}{l}\text { Lighters } \\
\text { collected }\end{array}$ & $\begin{array}{l}\text { Lighters not } \\
\text { collected }\end{array}$ \\
\hline Total & 191 & 100 & 91 \\
Cigarette & 144 & 71 & 73 \\
$\quad$ Disposable & 90 & 69 & 21 \\
Refillable & 2 & 1 & 1 \\
Unknown & 52 & 1 & 51 \\
Multipurpose & 46 & 29 & 17 \\
Unknown & 1 & 0 & 1
\end{tabular}

Note: When lighters were not collected, types were identified by the fire service based on discussion with the occupants.

Maintaining the 1998 estimated per fire loss rates for cigarette lighter fires caused by children younger than age 5 shown in table 3, the 1998 fire losses prevented were estimated at 100 deaths, 660 injuries, and $\$ 52.5$ million in property loss. Total societal cost prevented was estimated at $\$ 566.8$ million for 1998.

\section{Types of cigarette lighters involved in post-standard \\ fires}

Among 191 lighter fires ignited by children younger than age 5 in the post-standard data collection, 144 involved cigarette lighters, 46 involved multipurpose lighters, and one could not be identified (table 5). Among the 92 cigarette lighters that could be identified as either disposable or refillable, two (2\%) were refillable, the same proportion as in the pre-standard data. Cigarette lighters are often destroyed in fires to the extent that the type cannot be identified.

Disposable cigarette lighters operated by children younger than age 5, when collected, were evaluated to determine if the child resistant feature had been defeated. Of the 69 disposable lighters collected, 59 were manufactured with a child resistant mechanism and 10 were not. The child resistant features had been defeated on 13 of the 59 lighters (22\%) It was not possible to determine whether the 10 lighters manufactured without child resistant features were illegally manufactured or imported after the standard took effect or whether they were older, pre-standard, models.

\section{Multipurpose lighters}

The estimates of lighter fires shown in table 3 additionally identified the recent involvement of multipurpose lighters as a contributor to lighter child play fires and fire losses. Children younger than age 5 playing with multipurpose lighters caused an estimated 800 fires, 20 deaths, 50 injuries, and \$15.6 million in residential property loss in 1998. There was no product safety standard addressing those incidents at the time.

\section{DISCUSSION}

It is estimated that the CPSC Safety Standard for Cigarette Lighters reduced cigarette lighter child play fires caused by children younger than age 5 by $58 \%$. This conclusion is based on the assumption that, after adjusting for changes in the population, the standard is the only known factor that affects child play fires involving the younger age group but not the older age group. Many factors are believed to contribute to the general reduction of residential fires over the years but they are unlikely to affect younger children more than older children. These factors include public education, improvements in building construction, reductions in the size of the smoking population, and the increased presence of smoke alarms. It may be expected that the increased presence of smoke alarms would increase the proportion of fires that did not require the presence of the fire service. However, once a fire reaches the threshold level that results in fire service attendance, those captured for this analysis, it is not clear that the greater presence of smoke alarms changes the risk equation for the two age groups.

Taking into account the estimated fire losses that would have occurred if the standard had no effect, it is estimated that the CPSC safety standard was responsible for reductions of 3300 fires, 100 deaths, 660 injuries, and \$52.5 million in property loss in 1998. These reductions represent total 1998 societal savings of $\$ 566.8$ million. It is noted that these savings apply only to 1998 and that additional savings are expected in subsequent years.

To some extent these estimates may be conservative. First, children of ages 52-59 months were included in the group considered to be affected by the standard-that is, children younger than age 5 . However, because they were not included in the tests used to qualify lighters it cannot be concluded that the standard should be expected to protect them to the same extent. Second, the estimates included here refer only to fires attended by the fire service. To the extent that additional losses, mostly injuries and property damage, occurred in unreported fires, estimates of losses prevented are underestimated. Third, despite the expectation that homes would be fully saturated with child resistant lighters by 1998, review of the lighters involved indicated that some lighters were not child resistant. If all the lighters in homes had been child resistant, the effectiveness of the standard would have been greater than estimated. It is reasonable to expect that the number of pre-standard, non-child resistant lighters will continue to decline over time.

The 1997-99 study also documented that multipurpose lighters were a cause of child play fires, a hazard that was not evident when the cigarette lighter standard was developed. To address this hazard, CPSC developed the "Safety Standard for Multi-Purpose Lighters" (16 CFR Part 1212) which became effective on 22 December 2000, and includes the same child resistant performance requirements as the cigarette lighter standard. Since the performance requirements are the same as for cigarette lighters, proportionally similar savings may be expected in the future.

\section{IMPLICATIONS FOR PREVENTION}

These results document the value of the US standard in reducing fire deaths caused by children playing with cigarette 


\section{Key points}

- Fires, deaths, and injuries caused by young children play ing with cigarette lighters have been reduced as a result of the standard requiring child resistant lighters.

- Casualties could be prevented in other countries by adoption of a child resistant lighter standard with similar requirements.

- The standard is not a substitute for parental supervision.

- Continuing media campaigns are needed to inform caregivers that some young children, and most older children, can still operate cigarette lighters.

- Lighter safety campaigns should specify both cigarette lighters and multipurpose lighters.

lighters. To our knowledge, only Canada has a similar standard in effect, although discussions are underway in several other countries and in the European Union. Based on the US experience, adoption of a child resistant lighter standard by other countries could be expected to reduce fire deaths to children in those countries.

Many fire deaths involving lighters remain. Increased efforts to educate parents could help further reduce cigarette lighter deaths and injuries caused by child play. Messages should focus on two issues-first, the effectiveness of the standard, to encourage parents not to remove the child resistant feature, and second, the limitations of the standard. Parents may not be aware that some children as young as age 2 have been known to operate lighters, or that the child resistant features may not be equally effective for older children. Also, the CPSC standard is intended to make cigarette lighters child resistant, but not child proof. While the standard can increase the time needed for a child to operate the lighter, it may not prevent some children from operating the lighters with enough practice. Given the similarity of the hazard and performance requirements, educational materials addressing child play fires should specifically include multipurpose lighters since it may not be evident to parents that multipurpose lighters pose the same hazard.

\section{ACKNOWLEDGEMENTS}

The opinions expressed by the authors do not necessarily represent the views of the US CPSC. Since this material was written in the authors' official capacities it is in the public domain and, in accordance with 17 USC 1005, may be freely copied or reprinted. The authors acknowledge the contribution of the reviewers who provided comments to improve the earlier draft.

This material as well as additional material on the subject are contained in the report Fires Caused by Children Playing with Lighters: An Evaluation of the the CPSC Safety Standard for Cigarette Lighters, September 2000. The report is available at www.cpsc.gov/library.

\section{Authors' affiliations}

L E Smith, M A Greene, H A Singh, Hazard Analysis Division, Directorate for Epidemiology, US Consumer Product Safety Commission, Bethesda, Maryland

\section{REFERENCES}

1 Smith L, Smith C, Ray D. Lighters and matches: an assessment of risk associated with household ownership and use. Washington, DC: US Consumer Product Safety Commission, June 1991.

2 Homan Anthony. Market sketch-cigarette lighters. Washington, DC: US Consumer Product Safety Commission, 20 August 1990.

3 Homan A. Average product life of disposable lighters is estimated at two to three months. Product life for refillable lighters was estimated at 3 to 7 years. CPSC memorandum "Market sketch-cigarette lighters". Washington, DC: US Consumer Product Safety Commission, 20 August 1990 and data compiled from staff conversations with manufacturers.

4 Harwood B. Fire hazards involving children playing with cigarette lighters. Washington, DC: US Consumer Product Safety Commission, September 1987

5 Fleiss JL. Statistical methods for rates and proportions. 2nd Ed. New York: John Wiley and Sons, 1981: 63. (The population odds ratio, based on the US Census, is treated as a scaling constant in this formula.) 6 Karter MJ Jr. 1998 Fire loss in the United States. NFPA Journal 1999(sept/oct): 89-95.

7 Fire in the United States, 1989-1998. 12th Ed. Washington, DC: National Fire Data Center, US Fire Administration, Federal Emergency Managememt Agency, 2001: 17-27 (report may be obtained through the USFA web site: http://www.usfa.fema.gov/usfapubs).

8 Izrael D, Hoaglin DC, Battaglia MP. A SAS macro for balancing a weighted sample. Paper 258 SUGI (SAS Users Group International) 25. Cambridge, MA: Abt Associates, 2000 (available from authors).

9 Little RJA, Rubin DB. Statistical analysis with missing data. New York: John Wiley, 1987: 59

10 Hall JR Jr, Harwood B. The national estimates approach to US fire statistics. Fire Technology 1989;25(2):99-113.

11 Viscusi WK. The value of risks to life and health. Journal of Economic Literature 1993;xxx: 1912-46.

12 Miller TR. Societal costs of cigarette fires. Calverton, MD: Public Services Research Institute, Pacific Institute for Research and Education, 1993. 